\title{
Tribulus terrestris Saponins Improve Ovarian Ischemia-reperfusion Injury in Female Rats: Modulation of Vascular Endothelial Growth Factor-A and Hemeoxygenase-1
}

\author{
Asmaa Mohamed Abdel-Aziz', ${ }^{1, *}$, Hanaa Hassanein Mohammed², Osama Abdelazem², \\ Rasha Fouad Ahmed ${ }^{4}$, Yasmine F. Ibrahim ${ }^{1}$ \\ ${ }^{1}$ Department of Pharmacology, Faculty of Medicine, Minia University, Minia, EGYPT. \\ ${ }^{2}$ Department of Histology and Cell Biology, Faculty of Medicine, Minia University, Minia, EGYPT. \\ ${ }^{3}$ Department of Obstetrics and Gynecology, Faculty of Medicine, Al-Azhar University, Assuit, EGYPT. \\ ${ }^{4}$ Department of Medical Biochemistry, Faculty of Medicine, Minia University, Minia University, Minia, EGYPT.
}

\begin{abstract}
Aim/Background: Ovarian $\mathrm{I} / \mathrm{R}$ is a popular gynecological emergency, complicating ovarian torsion. TTS, reported to have many therapeutic effects along with being an antioxidant, anti- inflammatory and anti-apoptotic agent. The aim of this study was to estimate the probable protective role of Tribulus terrestris Saponin (TTS) in recovering the damaging effects of ischemia-reperfusion $(I / R)$ in the female rats' ovarian tissue. Materials and Methods: TTS was treated to female rats in presence or absence of ovarian I/R. Results: I/R caused ovarian damage, represented by deformity in normal ovarian histological structure, with a significant oxidative and nitrosative stress along with obvious inflammatory damage. Pretreatment with TTS significantly reversed the I/R induced ovarian toxic effects. TTS may have valuable ovarian protective effects against ovarian I/R injury. Conclusion: TTS protection is given via antioxidant, anti-nitrosative, anti-inflammatory and anti-apoptotic mechanisms with advancement of vascular angiogenesis and pituitary-gonadal axis up regulation.
\end{abstract}

Key words: Apoptosis, Angiogenesis, Immunohistochemical study, Ovarian ischemia/ reperfusion, Tribulus terrestris saponin.

\section{INTRODUCTION}

Ovarian torsion is believed to be the fifth cause for gynecological emergency in the medical field, known to be a partial or total rotation of the ovary around its ligaments; its incidence is almost $2.7 \% .{ }^{1} \mathrm{It}$ is considered to be a serious problem presented in women of all age groups, mainly in women of reproductive age; presented with nonspecific symptoms which considered to be the cause of delayed diagnosis in most cases. $^{2}$

The hypoxic period lasted for 3 days in mice and for 5 days in humans resulted in massive follicle loss. Therefore, effective angiogenic factors as vascular endothelial growth factor (VEGF) are needed to induce revascularization. ${ }^{3}$

Surgery with detorsion is the pole of treatment; aiming to restore the ovarian blood supply again, however, ovarian injury exacerbation occurred owing to the increase in free oxygen radicals production, inflammation along with endothelial damage. $^{4}$

Numerous experimental and clinical studies are executed to conquer this damage, but till now, no satisfactory treatment for the ovarian ischemia reperfusion (I/R) injury is present. $^{5}$
Submission Date: 20-11-2019; Revision Date: 30-05-2020; Accepted Date: 20-01-2021

DOI: 10.5530/ijper.55.1.27 Correspondence:

Dr. Asmaa Mohamed Abdel-Aziz

Lecturer, Department of Pharmacology, Faculty of Medicine, Minia University, 61511 Minia, EGYPT. Phone: +20 1002710831 E-mail: asmaaabdelaziz303@yahoo.com

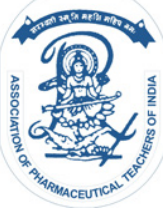

www.ijper.org 
Tribulus terrestris is an annual plant in the caltrop family (Zygophyllaceae) widely distributed around the world. Since ancient times was considered to have aphrodisiac, vasodilatory, anti-apoptotic, anti-inflammatory and antioxidant properties. Tribulus terrestris saponin (TTS) is the main effective component of Tribulus terrestris. ${ }^{6-9}$

There is a poverty of data concerning the effects of TTS on the female reproductive system; just an auspicious data proposed that TTS accelerates the puberty in immature female rats. ${ }^{8}$ These results promote us to explore the possible protective effects of TTS in prevention of ovarian I/R injury and its effect on ovarian function in mature female rat.

Hemeoxygenase-1 (HO-1); an enzyme induced by a variable stresses such as hypoxia, bacterial toxin, nitric oxide (NO) and I/R injury; giving a powerful protective effects in different models of tissue injury and in numerous disciplines including the CNS, cardiovascular physiology, renal and hepatic systems. It has been shown that the endogenous induction of HO-1 is included in different ovarian physiological processes as production of ovarian steroids and its deficiency is related to ovarian damage and insufficient ovulation. ${ }^{10}$ Cheng and Rong ${ }^{11}$ confirmed the protective effect of $\mathrm{HO}-1$ in variable models of $\mathrm{I} / \mathrm{R}$ injury but its value in ovarian I/R hasn't been studied yet.

\section{MATERIALS AND METHODS}

Pure TTS extract (hydroethanolic extract) was kindly prepared from Nerhadou international Pharmaceutical Co. (Sopharma AD, Bulgaria). The extraction was made using $70 \%$ ethanol so that $100 \mathrm{~g}$ of dry extract would be obtained from $735 \mathrm{~g}$ of the plant and was freshly prepared prior to use in distilled water vehicle. ${ }^{9}$ D.dimer enzymelinked immunosorbent assay (ELISA) kit was purchased from ELISA Genie Co. (Dublin, Ireland). TNF- $\alpha$ ELISA kit was purchased from Sigma-Aldrich Co. (St. Louis, MO, USA). FSH, LH, AMH and VEGF-A ELISA kits were purchased from Elabscience Biotecnololgy Inc. Caspase-3 rabbit polyclonal antibodies was purchased from Sigma-Aldrich Co. (St. Louis, MO, USA).

\section{Animals}

Thirty two adult female Wistar rats weighing 250-300 g were purchased from the animal house, Giza, Egypt. Rats were allowed to acclimatize for 1 week before use in the experiment. Animals were kept in convenient housing conditions in cages and were supplied with rat chow [supplemented with $18 \%$ proteins, 3\% lipids and 10\% fibers] and tap water. The animals were housed between $20^{\circ} \mathrm{C}$ and $22^{\circ} \mathrm{C}$ with a $12 \mathrm{hr}$ light/12 hr dark cycle. This study was conducted in the Pharmacology Department, Faculty of Medicine, Minia University, Egypt. Procedures involving rats complied with the ARRIVE guidelines and the board of faculty of medicine, Minia university and the EU Directive, approved the procedures of animal experiment protocol (144:12/2018).

\section{Experimental design}

Rats were randomly divided into 4 groups $(n=8$ each group): Group I: sham group subjected to all operative procedures without ovarian I/R, received distilled water as a vehicle once orally for two weeks. Group II: sham pretreated with TTS $(2.25 \mathrm{~g} / \mathrm{kg} /$ day $)$ once orally for two weeks, subjected to all operative procedures without ovarian I/R.

Group III: I/R group received distilled water as a vehicle once orally for two weeksthen ovarian $I / R$ was induced. Group IV: I/R group pretreated with TTS $(2.25 \mathrm{~g} / \mathrm{kg} /$ day $)$ once orally for two weeks then ovarian $\mathrm{I} / \mathrm{R}$ was done. ${ }^{9}$

\section{Experimental ovarian V/R procedure}

The rats were weighed and anesthetized using intramuscular ketamine $(50 \mathrm{mg} / \mathrm{kg})$ then, the rats were kept in a supine position with application of $2 \%$ iodine alcohol to lower abdominal region. A longitudinal incision of $2.5 \mathrm{~cm}$ was done, bilateral ovarian ischemia was induced by the use of vascular clips below the ovaries then closure of the incision line with 4-0 nylon sutures was done. Three hours after ischemia, reperfusion was done by removing the vascular clamps for $3 \mathrm{hr}^{5}$ Scarification was done by cervical incision and venous blood samples were collected, centrifuged at $5000 \mathrm{rpm}$ for $15 \mathrm{~min}$. Serum was collected and stored at $-80^{\circ} \mathrm{C}$ until used. The rats' ovaries were cleaned by washing in $0.9 \%$ saline solution and were divided into two parts, one part was frozen at $-80^{\circ} \mathrm{C}$ for biochemical analysis and the other was kept in formalin for histopathological examination.

\section{Preparation of ovarian homogenate}

The ovarian tissues were weighed then homogenized in ice cold phosphate buffer saline solution, then the homogenate was centrifuged for $15 \mathrm{~min}$ at $4^{\circ} \mathrm{C}$ in a cooling centrifuge and the supernatant was kept at $-80^{\circ} \mathrm{C}$ until use.

\section{Hormonal Assay}

Follicle-Stimulating Hormone (FSH), Luteinizing Hormone (LH) and $\mathrm{AMH}$ were quantitatively evaluated in serum samples using ELISA kits according to the manufacturer instructions, Catalog No: E-EL-R0391, E-EL-R0026 and E-EL-R0640. 


\section{Assessment of ovarian oxidative stress parameters}

According to the method previously prescribed by Marklund and Marklund, ${ }^{12}$ SOD activity was measured at $420 \mathrm{~nm}$ by a spectrophotometer.

Reduced glutathione (GSH) measurement rely on that the sulfhydryl groups of GSH react with 5,5-dithio-bis2-nitrobenzoic acid (Ellman's reagent), giving a yellow colored 5-thio-2-nitrobenzoic acid. The color density was colorimetrically detected at $405 \mathrm{~nm}$ using Beckman DU-64 UV/VIS spectrophotometer, USA. ${ }^{13}$

Lipid peroxidation is based upon thiobarbituric acid reacting substance which is expressed as equivalents of malondialdehyde (MDA), by using 1, 1, 3, 3tetramethoxypropane as standard. ${ }^{14}$

Measurement of $\mathrm{NOx}$ is based upon conversion of nitrate to nitrite by copperized cadmium granules using spectrophotometer at $540 \mathrm{~nm} .^{15}$

\section{ELISA assay}

D.dimer, TNF- $\alpha$ and VEGF-A levels in ovarian homogenate were detected by ELISA kits according to the manufacturer's instructions, Catalog No: RTFI00722, E-EL-R0019 and E-EL-R2603 respectively.

\section{Histopathological and immunohistochemistry evaluation}

Ovarian tissue sections were taken, fixed in 10\% neutral buffered formaldehyde for 48 hours and embedded in paraffin wax. $5 \mu \mathrm{m}$ cross sections were cut and stained with hematoxylin and eosin (H\&E). ${ }^{16}$

Immunocytochemical staining was done using polyclonal rabbit antibodies for anti-cleaved caspase-3 antibody (PA1-26426) according to a previously described method of El-Sheikh et al. ${ }^{17}$

Olympus light microscopy (Olympus, Japan) was used for examination and capturing photos for the histological and immunohistochemical sections. Slides were photographed by Olympus digital camera. Images were saved as jpg and processed by Adobe Photoshop 7.

\section{Morphometric study}

Congestion, hemorrhage, leukocyte infiltration, follicular degeneration, interstitial edema and necrosis in the corpus luteum were scored ranged from 0 to 3 according to the severity of injury, where 0 represented no pathologic findings while 1,2 and 3 represented minimal, moderate and severe pathologic findings of the ovarian section, respectively. ${ }^{18}$ The examiner was blinded to the different treated groups.
Semi-quantitative data were evaluated in all studied groups for the mean number of caspase-3 immunopositive cells. Brown cytoplasmic staining of ovarian cells was recorded as positive $(+)$ and scored using a semiquantitative scale, where 0 represented no staining and $1+, 2+$ and $3+$ represented staining $<33 \%, 33-66 \%$ and $>66 \%$ of the ovarian section, respectively. It was counted per section in 10 randomly selected nonoverlapping fields at power X 400 magnifications of the sections from each rat. The examiner was blinded to the different treated groups. ${ }^{19}$

\section{Quantitative real-time polymerase chain reaction (RT-PCR)}

Total RNA was extracted from homogenized ovarian specimen by use of ribozol RNA extraction reagent according to the manufacturer's instructions. cDNAs were synthesized by Revert Aid ${ }^{\text {TM }}$ First Strand cDNA Synthesis kit. cDNA was transcribed reversely from 5 $\mu \mathrm{g}$ of RNA in a thermal cycler at $42^{\circ} \mathrm{C}$ for $60 \mathrm{~min}$ then $70^{\circ} \mathrm{C}$ for $5 \mathrm{~min}$ according to the kit protocol. The SYBR green data were analyzed with a relative quantification to GAPDH (Glyceraldehyde-3-phosphate dehydrogenase) as a reference gene. ${ }^{20}$ The sets of primers used were as follows:

GAPDH primers

Forward: 5' GTCGGTGTGAACGGAT'TTG3'

Reverse: 5' CT'TGCCGTGGGTAGAGTCAT3'

HO-1 primers

Forward primer: $5^{\prime}$

TAGGTGTGATCTTAACTGTCG3'

Reverse primer: 5' GCATGGTGTAGATGATCTCA3'

$\mathrm{NF}-\mathrm{kB}$ primer

Forward primer: $5^{\prime}$

'TAGGTGTGATCTTAACTGTCG3'

Reverse primer: 5' GCATGGTGTAGATGATCTCA3'

iNOS primers:

Forward: 5' TGTGACACACAGCGCTACAA 3'

Reverse: 5' 'TGTTGAAGGCGTAGCTGAAC3'

\section{Statistical analysis}

Data was analyzed by one way ANOVA followed by Tukey's test. The values are represented as means \pm SEM. Statistical analysis was performed using GraphPad Prism software (version 5). The differences were considered significant if $P$ value is $<0.05$.

\section{RESULTS}

Effect of T'TS on serum FSH, LH, AMH and D.dimer levels 
Ovarian I/R significantly increased serum FSH, LH and D.dimer levels with significant decrease in AMH level if compared to control group. Rats pretreated with TTS showed a significant decrease in FSH, LH and D.dimer levels with significant increase in AMH level compared to I/R group (Table 1).

\section{Effect of TTS on ovarian oxidative stress parameters}

In comparison with the control group, ovarian I/ R caused a significant decrease in ovarian tissue GSH level and SOD activity however; it increased the MDA and NOx levels. TTS pre administration to ovarian $\mathrm{I} / \mathrm{R}$ induced rats significantly increased both GSH and SOD with decrease in both MDA and NOx levels in comparison to ovarian I/R non treated group (Table 2).

\section{Effect of TTS on TNF-a and VEGF-A expression in ovarian tissue}

There was a significant increase in ovarian tissue content of TNF- $\alpha$ in $\mathrm{I} / \mathrm{R}$ group when compared

Table 1: Effect of Tribulus terrestris saponins on serum AMH, FSH, LH and D.Dimer.

\begin{tabular}{|c|c|c|c|c|}
\hline & $\begin{array}{c}\text { AMH } \\
(\mathbf{n g} / \mathbf{m l})\end{array}$ & $\begin{array}{c}\text { FSH } \\
\text { (IU/L) }\end{array}$ & $\begin{array}{c}\text { LH } \\
\text { (IU/L) }\end{array}$ & $\begin{array}{c}\text { D.Dimer } \\
\text { (ng/ml) }\end{array}$ \\
\hline Sham & $3.0 \pm 0.1$ & $2.4 \pm 0.3$ & $1.1 \pm 0.1$ & $28.6 \pm 0.9$ \\
\hline TTS & $3.0 \pm 0.1$ & $2.6 \pm 0.2$ & $1.1 \pm 0.1$ & $29.3 \pm 1.8^{-1}$ \\
\hline I/R & $1.6 \pm 0.1^{\mathrm{a}}$ & $9.0 \pm 0.7^{\mathrm{a}}$ & $5.8 \pm 0.4^{\mathrm{a}}$ & $50.9 \pm 2.3^{\mathrm{a}}$ \\
\hline TTS+I/R & $2.5 \pm 1^{\mathrm{b}}$ & $3.8 \pm 0.4^{\mathrm{b}}$ & $2.8 \pm 0.4^{\mathrm{b}}$ & $36.7 \pm 1.8^{\mathrm{b}}$ \\
\hline F (df) & 71.53 & 53.75 & 49.20 & 34.11 \\
\hline
\end{tabular}

Values are presented as mean \pm S.E.M ( $n=8$ rats). Results are considered

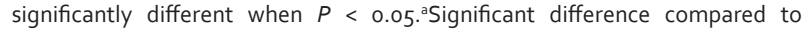
control, bsignificant difference compared to $\mathrm{I} / \mathrm{R}$ group. $A M H=$ anti mullerian hormone, FSH = Follicle-stimulating hormone, $\mathrm{LH}=$ luteinizing hormone, TTS= Tribulus terrestris Saponins, $I / R=$ ischemia/reprfusion and $d_{f}$ degree of freedom.

\section{Table 2: Effect of Tribulus terrestris saponins on} oxidative stress parameters in ovarian tissue.

\begin{tabular}{|c|c|c|c|c|}
\hline & $\begin{array}{c}\text { SOD (U/g } \\
\text { tissue) }\end{array}$ & $\begin{array}{c}\text { MDA } \\
\text { (nmol/g } \\
\text { tissue) }\end{array}$ & $\begin{array}{c}\text { GSH } \\
(\mathbf{\mu m o l} / g \\
\text { tissue) }\end{array}$ & $\begin{array}{c}\text { NOx } \\
\text { (nmol/ } \\
\text { gtissue) }\end{array}$ \\
\hline Sham & $2314 \pm 102.9$ & $15.8 \pm 1.9$ & $248.8 \pm 3.5$ & $34.9 \pm 3.4$ \\
\hline TTS & $2094 \pm 156.4$ & $19.5 \pm 3.7$ & $240.1 \pm 15.9$ & $34.7 \pm 3.3$ \\
\hline I/R & $940.4 \pm 24.9^{\mathrm{a}}$ & $44.2 \pm 3.0^{\mathrm{a}}$ & $71.6 \pm 5.8^{\mathrm{a}}$ & $89.3 \pm 4.3^{\mathrm{a}}$ \\
\hline TTS+I/R & $1890 \pm 114.8^{\mathrm{b}}$ & $20.9 \pm 2.1^{\mathrm{b}}$ & $193.5 \pm 12.1^{\mathrm{b}}$ & $42.4 \pm 4.3^{\mathrm{b}}$ \\
\hline $\mathbf{F}$ (df) & 29.94 & 21.46 & 59.67 & 45.80 \\
\hline
\end{tabular}

Values are presented as mean \pm S.E.M ( $n=8$ rats). Results are considered

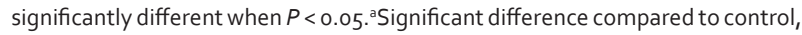

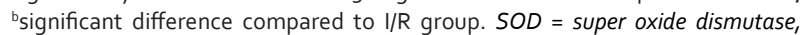
$G S H=$ reduced glutathione, $M D A=$ manoldialdahyde, $N O x=$ total nitrite/nitrate, TTS = Tribulus terrestris saponins, $I / R=$ ischemia/reprfusion and $d_{f}$ degree of freedom. with control group. Pretreatment with TTS showed a significant decrease in ovarian tissue content of TNF- $\alpha$ in comparison with $\mathrm{I} / \mathrm{R}$ group. As compared to the control group, ovarian I/R caused significant decrease in ovarian tissue VEGF-A level while; administration of TTS to ovarian I/R induced rats significantly increased VEGF-A level in comparison to ovarian $\mathrm{I} / \mathrm{R}$ non treated group (Table 3)

\section{Effect of TTS on HO-1, NF-kB and iNOS gene expression changes in ovarian tissue}

A significant decrease in HO-1 gene expression in induced ovarian $\mathrm{I} / \mathrm{R}$ rats was found with a significant elevation in TTS pretreated group in comparison to ovarian I/R group. Both NF- $x \mathrm{~B}$ and iNOS gene expression in ovarian $\mathrm{I} / \mathrm{R}$ group significantly increased in comparison with control group, while there is a significant decrease in their expression in T'TS pretreated group in comparison with ovarian I/R group (Table 4).

\section{Histopathological study}

Ovarian I/R showed significant injury to ovarian tissue compared to control group. Rats pretreated with TTS

\begin{tabular}{|c|c|c|}
\hline & TNF- $\alpha(p g / m l)$ & VEGF-A (pg/ml) \\
\hline Sham & $38.7 \pm 2.3$ & $63.9 \pm 1.8$ \\
\hline TTS & $37.8 \pm 1.4$ & $63.8 \pm 2.3$ \\
\hline I/R & $71.6 \pm 2.8^{a}$ & $41.7 \pm 2.7^{\text {a }}$ \\
\hline TTS+I/R & $46.3 \pm 3.9^{b}$ & $56.3 \pm 1.9^{b}$ \\
\hline$F(d f)$ & 32.37 & 22.13 \\
\hline
\end{tabular}

Values are presented as mean \pm S.E.M ( $n=8$ rats). Results are considered

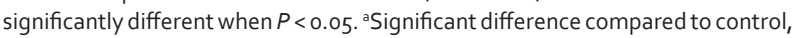
bsignificant difference compared to I/R group. VEGF- $A=$ vascular endothelial growth factor- $A, T N F-\alpha=$ tumor necrosis factor, TTS = Tribulus terrestris saponins, $I / R=$ ischemia/reprfusion and $d_{f}$. degree of freedom.

Table 4: Effect of Tribulus terrestris saponins on HO1, iNOS and NF-kB gene expression.

\begin{tabular}{|c|c|c|c|}
\hline Sham & $\begin{array}{c}\text { HO-1 gene } \\
\text { expression }\end{array}$ & $\begin{array}{c}\text { iNOS gene } \\
\text { expression }\end{array}$ & $\begin{array}{c}\text { NF-kB gene } \\
\text { expression }\end{array}$ \\
\hline TTS & $10.4 \pm 0.7$ & $1.9 \pm 0.3$ & $2.3 \pm 0.4$ \\
\hline I/R & $4.7 \pm 0.5^{\mathrm{a}}$ & $7.9 \pm 0.6^{\mathrm{a}}$ & $11 \pm 0.7^{\mathrm{a}}$ \\
\hline TTS/I/R & $7.8 \pm 0.5^{\mathrm{b}}$ & $5.6 \pm 0.5^{\mathrm{b}}$ & $5.1 \pm 0.5^{\mathrm{b}}$ \\
\hline F (df) & 21.15 & 50.85 & 70.93 \\
\hline
\end{tabular}

Values are presented as mean \pm S.E.M ( $n=8$ rats). Results are considered

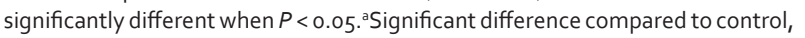
${ }^{\mathrm{b}}$ significant difference compared to $\mathrm{I} / \mathrm{R}$ group. $\mathrm{HO}-1=$ Hemeoxygenase -1 , iNOS= inducible nitric oxide synthase, NF-kB= nuclear factor kappa beta, TTS= Tribulus terrestris saponins, $I / R=i$ schemia/reprfusion and $d_{f}$ degree of freedom. 
showed a significant histological elaboration compared with I/R group (Figure 1).

Caspase-3 immunohistopathological study of control group showed negative cytoplasmic immunoreactivity in ovarian tissue while sections from I/R show extensive cytoplasmic reaction which were significantly improved in TTS pretreated group (Figure 2).

\section{DISCUSSION}

Ovarian ischemia as a consequence of torsion represents a gynecological emergency affecting young females during reproductive age. Its management by detorsion results in ovarian $\mathrm{I} / \mathrm{R}$ injury. Thus, a conservative treatment with detorsion is highly recommended. ${ }^{21}$ Therefore, we attempted to investigate the effect and underlying mechanisms of TTS treatment against ovarian I/R injury.

Depletion of the energy stores occurs during ovarian torsion, leads to collection of the toxic metabolites. Along with ovarian detortion and recuperation of the blood flow to the ischemic tissue; activation of
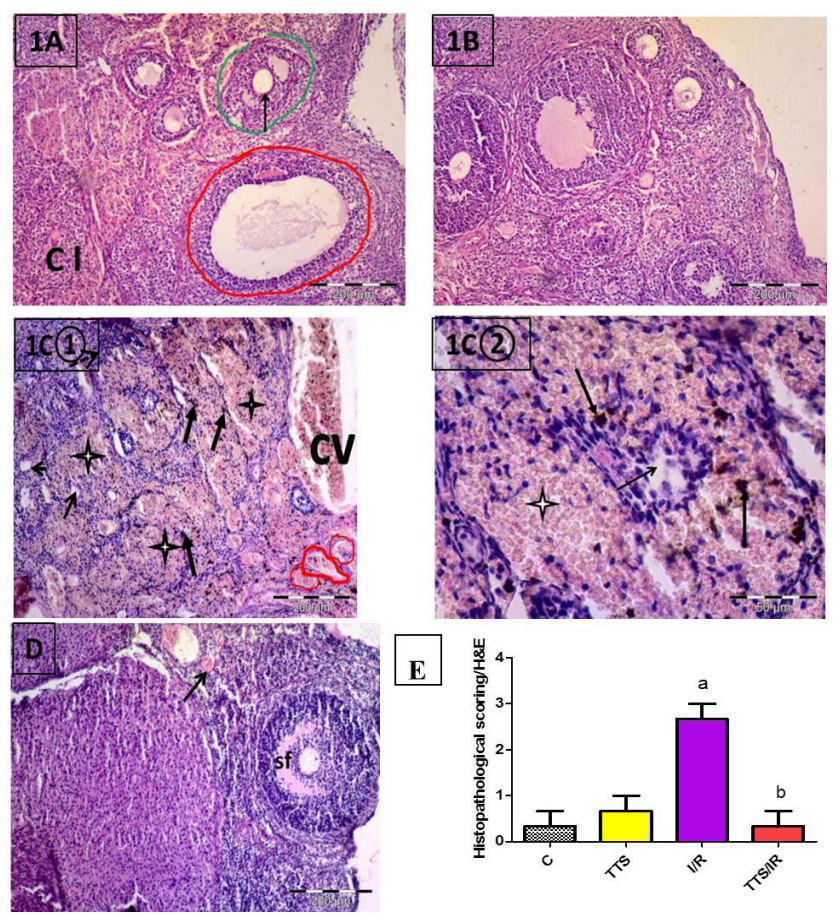

Figure 1: Histopathology of ovarian tissue.

Photomicrographs of ovarian sections of control and TTS groups (Figure $1 \mathrm{~A}$ and $\& B$ ) respectively show the same morphological pictures of Corpus Iuteum (c 1), a secondary follicles (lined by green) with the intact oocyte zona pellucida (arrow) and a mature Graafian follicle (lined by red) H\&E (X100). I/R group (Figure 1 C (1) and (2)) showing hemorrhage (black stars), degenerated follicles (lined by red), edema (arrow), congested vessel (cv), cellular infiltration (dashed arrow) and hemosiderin laden macrophages (thick closed arrow) (H\&E (1) X100, (2) X400). In TTS/IR group (Figure 1D) shows more or less normal ovarian structure of healthy secondary follicles (SF) and little congestion (arrow). H\&E (X100). Values are presented as mean \pm S.E.M ( $\mathrm{n}=8$ rats). Results are considered significantly different when $P<0.05$. ${ }^{a}$ Significant difference compared to control, bsignificant difference compared to I/R group. neutrophils with release of reactive oxygen species (ROS) in the ischemic tissue occur; activating pro inflammatory cytokines and leucocytes, disrupting capillary walls via lipid peroxidation, protein oxidation; causing DNA damage, amplification of the inflammatory process, ovarian injury with suppressed functional capacity occurred. ${ }^{22}$

In the current study, ovarian I/R disturbed the oxidative stress/antioxidant balance with increased levels of oxidative and nitrostive stress biomarkers MDA and NO. It also decreased the antioxidant enzyme SOD activity and non-enzymatic antioxidant GSH level in ovarian I/R group compared to control one which matches with other previous studies. ${ }^{11,23}$

HO-1; a stress-inducible enzyme, catalyzes the degradation of heme into carbon monoxide (CO), iron and biliverdin. ${ }^{24}$ Under oxidative stress and inflammation, HO-1 is induced and protects organs from damage. ${ }^{25} \mathrm{HO}-1$ gene expression in the present study was significantly lower in I/R group compared to control group reflecting its ovarian depletion during $\mathrm{I} / \mathrm{R}$ induced oxidative stress, in line with other previous studies. ${ }^{11}$

TTS pretretment significantly over expressed the HO-1 in the treated group compared to I/R-non treated one. HO-1 over expression has an antioxidant and anti-inflammtory activities via heme metabolism. The bilirubin converted from biliverdin and the CO exhibit antioxidant activity, vasodilation and
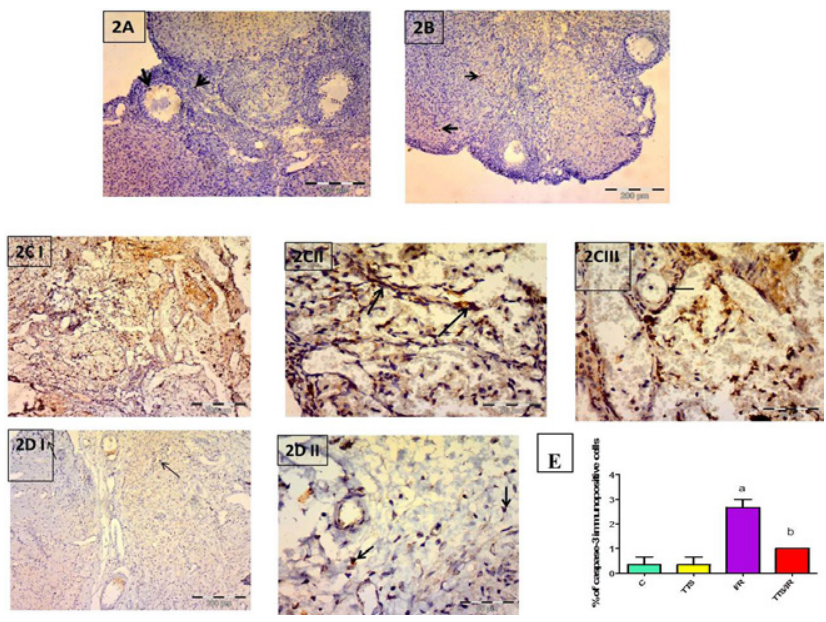

Figure 2: Immunostaining of caspase-3 in ovarian tissue. Photomicrographs of rat ovarian sections from control and TTS groups (Figure $2 \mathrm{~A}$ and B) showing very little immunoreactivity for caspase-3 (arrow) (caspase-3 immunostaining: X100). I/R group (Figure 2 C I, II \& III), the ovarian tissue showing strong immunoreactivity for caspase-3 (appears as brown color, C II expression in stromal cells and CIII expression in follicular cells; arrows) (caspase- 3 immunostaining: I: X100, II\&III: X400). In TTS/IR group (Figure 2 D I \& II) showing the ovarian tissue contained scanty immunoreactivity for caspase-3 (arrows). (Caspase-3 immunostaining I: X100, II: X400). Values are presented as mean \pm S.E.M ( $\mathrm{n}=8$ rats). Results are considered significantly different when $P<0.05$. ${ }^{a}$ Significant difference compared to control, bSignificant difference compared to I/R group. 
inhibition of platelet aggregation. Moreover, $\mathrm{CO}$ has anti-inflammatory through inhibition of cytokine production ${ }^{26}$ and anti-apoptotic properties. ${ }^{27}$ Therefore, HO-1 induction might be important in antioxidant and anti-inflammatory response exerted by TTS against ovarian I/R.

The inflammatory disorder occurs during ovarian $\mathrm{I} / \mathrm{R}$ as a consequence of ROS production, is initiated by the activation of various enzymes in ovarian tissue, which leads to ovarian follicle injury, followed by the release of many pro-inflammatory cytokines as TNF- $\alpha$ which exerts host-damaging effects and contributes to the systemic progression of the inflammatory response up to end-organ dysfunction. ${ }^{28}$ In the current study induction of ovarian $\mathrm{I} / \mathrm{R}$ was associated with increased TNF- $\alpha$ level along with increase in NF- $x \mathrm{~B}$ and iNOS gene expression in ovarian tissue of $\mathrm{I} / \mathrm{R}$ group compared to control group which matches with other previous studies. ${ }^{11,23}$

On the other hand, TTS pretreatment in the present study, decreased ovarian TNF- $\alpha$ along with decrease in NF- $x \mathrm{~B}$ and iNOS gene expression than I/R group reflecting its anti-inflammatory activity which is in agreement with previous studies. ${ }^{29,30}$

During I/R injury, TNF- $\alpha$ activates several apoptotic proteins stimulating the apoptotic degradation phase. ${ }^{31}$ The involvement of caspase enzyme family as a unique indicator makes them in the center of interest especially for new drug studies. Caspase-3, which was also immunohistochemically evaluated in our study, is considered an effector enzyme in starting death cascade and an important marker for cells undergoing apoptotic signal pathway. ${ }^{32}$

The current finding revealed an increase in ovarian expression of caspase- 3 level in $\mathrm{I} / \mathrm{R}$ rats and TTS pretreatment successfully decreased its expression which was in agreement with other studies. ${ }^{30}$

Hypothalamic neuroendocrine cells stimulate gonadotropic releasing hormone $(\mathrm{GnRH})$ release which stimulates $\mathrm{LH}$ and FSH secretion from the anterior pituitary gland. LH regulates hormone production and FSH is responsible for follicle development. ${ }^{33}$ In this study, we found that ovarian I/R increased FSH and LH levels as compared to control group due to loss of the ovarian germinative and hormonal functions owing to the exhaustion of the number of ovarian follicles, ${ }^{34}$ while TTS pretreatment contribute to restoring ovarian function, decreased FSH and LH secretion by the hypothalamic-pituitary-ovarian axis which may be due to increase in E2 induced by TTS treatment. The hormone production recovery prevented the primordial follicle pool from being abnormally depleted and these results matches with previous study of Tavana et al..$^{35}$ AMH expression starts from the granulosa cells of early antral follicles and suppressed when the follicles start to become atretic. ${ }^{36}$ In our study, ovarian I/R reduced AMH serum level, while its level increased when TTS was pre administered. Thus, TTS may preserve the proliferation capacity and implementation of follicles after ischemic injury which is in agreement of Dehghan et al. ${ }^{7}$ who explored that TTS can efficiently recover the ovarian activity.

D-dimer, a marker reflecting the degree of fibrin turnover, studied as a possible marker to detect an early ovarian torsion with a significant correlation between d-dimer level and the histopathological damage scores of ovarian injuries. ${ }^{2}$ In our study, ovarian I/R increased serum D-dimer level while TTS pretreatment was able to normalize $\mathrm{D}$-dimer level reflecting its ability to recover the $\mathrm{I} / \mathrm{R}$ ovarian damage.

VEGF-A besides being the chief regulator of vascular angiogenesis, it is a direct activator for ovarian follicle, neutralizing VEGF-A activity outface the follicular development and ovulation, ${ }^{37}$ while administering VEGF-A increases the number of pre-ovulatory follicles and the frequency of ovulation and decreases the number of atretic follicles. ${ }^{38}$

We proved in our study that TTS retrieve the ovarian follicle from $I / R$ injury, as it increased VEGF-A expression in ischemic ovarian tissue which may increases the number of ovarian follicles with restoration of the germinative and hormonal functions. Although how VEGF-A protects against ischemic damage is not understood, Tunckiran et al. ${ }^{39}$ mentioned that VEGF-A protected the testicular I/R injury by inhibition of leukocyte recruitment and preventing the inflammatory damage in ischemic tissue.

By increasing VEGF-A expression, TTS may facilitate delivery of stem cells to the ovary, up regulate survival factors, or activate a yet unknown mechanisms which increases the ovarian follicle pool also, by increasing neovascularization, TTS preserve microvascular circulation and improve the tissue perfusion.

In conclusion, this study proved that TTS presented a potential new therapy for ovarian $I / R$ as it has the ability to protect the ovaries from ovarian ischemic injury and promoting their function with up regulation of the pituitary-gonadal axis, through down-regulation of NF- $x \mathrm{~B} / \mathrm{iNOS} / \mathrm{NO} / \mathrm{TNF}-\alpha$ pathway along with modulation of HO-1 and VEGF-A expression with inhibition of oxidative stress, inflammatory pathways, 
apoptotic pathways and promoting ovarian angiogenesis subsequently.

\section{ACKNOWLEDGEMENT}

The authors are thankful to the Faculty of Medicine, Minia University for their permissions, facilities, and infrastructure that allowed operating their research.

\section{CONFLICT OF INTEREST}

The authors declare that they have no competing interests.

\section{ABBREVIATIONS}

AMH: Anti mullerian hormone; CO: Carbon monoxide; ELISA: Enzyme-linked immunosorbent assay; FSH: Follicle-Stimulating Hormone; H\&E: Hematoxylin and eosin; HO-1: Hemeoxygenase -1; I/R: Ischemia reperfusion; LH: Luteinizing Hormone; MDA: Malondialdehyde; NO: Nitric oxide; ROS: Reactive oxygen species; RT-PCR: Real-time polymerase chain reaction; GSH: Reduced glutathione; TTS: Tribulus terrestris saponin; VEGF-A: Vascular endothelial growth factor-A.

\section{The limitations of the study}

The lack of facilities prevent us to investigate erythroid -related factor 2 (Nrf2) which induces the expression of hemoxygenase-1 and also, to investigate hypoxic ischemic factor- $1 \alpha$; an essential adaptive factor to hypoxia by regulating VEGF-A.

\section{REFERENCES}

1. Ozlem K, Birkan Y, Mustafa K, Emin K. Protective effect of Vaccinium myrtillus on ischemia-reperfusion injury in rat ovary. Taiwan J Obstet Gynecol. 2018;57(6):836-41.

2. Parlakgumus HA, Aka BF, Bulgan KE, Simsek E, Parlakgumus A. Atorvastatin for ovarian torsion: Effects on follicle counts, AMH and VEGF expression. Eur J Obstet Gynecol Reprod Biol. 2014;175:186-90.

3. Bei-Jia K. Yan W, Long Z, Zhun X, Shang-Wei L. BFGF and VEGF Improve the Quality of Vitrified-Thawed Human Ovarian Tissues After Xenotransplantation to SCID Mice. Assist Reprod Genet. 2016;33(2):281-9.

4. Yayla M, Cetin D, Adali Y, Kilicle PA, Toktay E. Potential therapeutic effect of pomegranate seed oil on ovarian ischemia/reperfusion injury in rats. Iran J Basic Med Sci. 2018;21(12):1262-8.

5. Dayangan SC, Karaca G, Sema OZ, Tulmac OB, Ceylan IA, Devrim T, et al. What is the protective effect of metformin on rat ovary against ischemiareperfusion injury?. J Obstet Gynaecol Res. 2018;44(2):278-85.

6. Shalaby MA, Hammouda AA. Assessment of protective and anti-oxidant properties of Tribulus terrestris fruits against testicular toxicity in rats. $J$ Intercult Ethnopharmacol. 2014;3(3):113-8.

7. Dehghan A, Esfandiari A, Bigdeli SM. Alternative treatment of ovarian cysts with Tribulus terrestris extract: A rat model. Reprod Domest Anim. 2012;47(1):e12-5.
8. Wang Z, Zhang D, Hui S, Zhang Y, Hu S. Effect of Tribulus terrestris saponins on behavior and neuroendocrine in chronic mild stress depression rats. J Tradit Chin Med. 2013;33(2):228-32.

9. Cui HY, Zhang XJ, Yang Y, Zhang C, Zhu CH, Miao JY, et al. Rosmarinic acid elicits neuroprotection in ischemic stroke via Nrf2 and heme oxygenase 1signaling. Neural Regen Res. 2018;13(12):2119-28.

10. Refaie MMM, El-Hussieny M. Protective effect of pioglitazone on ovarian ischemia reperfusion injury of female rats via modulation of peroxisome proliferator activated receptorgamma and heme-oxygenase 1. Int Immunopharmacol. 2018;62:7-14.

11. Cheng Y, Rong J. Therapeutic Potential of Heme Oxygenase-1/carbon Monoxide System against Ischemia-Reperfusion Injury. Curr Pharm Des. 2017;23(26):3884-98.

12. Marklund S, Marklund G. Involvement of the superoxide anion radical in the autoxidation of pyrogallol and a convenient assay for superoxide dismutase. The FEBS Journal. 1974;47(3):469-74.

13. Moron MS, Depierre JW, Mannervik B. Levels of glutathione, glutathione reductase and glutathione S-transferase activities in rat lung and liver. Biochim Biophys Acta. 1979;582(1):67-78.

14. Buege J, Aust S. Microsomal lipid peroxidation. Methods Enzymol. 1978;52:302-10.

15. Ridnour LA, Sim JE, Hayward MA, Wink DA, Martin SM, Buettner GR, et al. A spectrophotometric method for the direct detection and quantitation of nitric oxide, nitrite and nitrate in cell culture media. Anal Biochem. 2000;281(2):2239.

16. Suvarna KS, Layton C, Bancroft JD. Bancroft's Theory and Practice of Histological Techniques E- Book, $8^{\text {th }}$ edition. Elsevier Health Sciences China. 2018;40-60.

17. El-Sheikh AA, Morsy MA, Hamouda AH. Protective Mechanisms of Thymoquinone on Methotrexate-induced Intestinal Toxicity in Rats. Pharmacogn Mag. 2016;12(Suppl 1):S76-81.

18. Guven S, Muci E, Unsal MA, Yulug E, Alver A, Kadioglu DM, et al. The effects of carbon dioxide pneumoperitoneum on ovarian blood flow, oxidative stress markers and morphology during laparoscopy: A rabbit model. Fertil Steril. 2010;93(4):1327-32.

19. Cakir GAN, Gencer M, Karaca T, Hacivelioglu S, Uysal A, Korkmaz F, et al. The effect of hesperetin on ischemia-reperfusion injury in rat ovary. Arch Gynecol Obstet. 2014;290(4):763-9.

20. VanGuilder HD, Vrana KE, Freeman WM. Twenty-five years of quantitative PCR for gene expression analysis. Biotechniques. 2008;44(5):619-26.

21. Ali FF, Ahmed AF, Elroby ADM. Underlying mechanisms behind the protective effect of angiotensin (1-7) in experimental rat model of ovarian ischemia reperfusion injury. Life Sci. 2019;235:116840.

22. Tuncer AA, Bozkurt MF, Koken T, Dogan N, Pektaş MK, Baskin ED. The Protective Effects of Alpha-Lipoic Acid and Coenzyme Q10 Combination on Ovarian Ischemia-Reperfusion Injury: An Experimental Study. Adv Med. 2016;3415046.

23. Icel E, Icel A, Uçak T, Karakurt Y, Elpeze B, Keskin ÇF, et al. The effects of lycopene on alloxan induced diabetic optic neuropathy. Cutan Ocul Toxicol. 2018;23:1-5.

24. Nakamichi I, Habtezion A, Zhong B, Contag CH, Butcher EC, Omary MB. Hemin-activated macrophages home to the pancreas and protect from acute pancreatitis via heme oxygenase- 1 induction. The Journal of Clinical Investigation. 2005;115(11):3007.

25. Abdel-Gaber SA, Geddawy A, Moussa RA. The Hepatoprotective Effect of Sitagliptin against Hepatic Ischemia Reperfusion-induced Injury in Rats involves Nrf-2/HO-1 Pathway. Pharmacological Reports. 2019;71(6):1044-9.

26. Hang FH, Sun $\mathrm{YH}$, Fan KL, Dong XB, Han N, Zhao H, et al. Protective effects of heme oxygenase-1 against severe acute pancreatitis via inhibition of tumor necrosis factor- $\alpha$ and augmentation of interleukin-10. BMC Gastroenterology. 2017;17(1):1-7.

27. Bekyarova G, Tzaneva M. Melatonin Ameliorates Burn-Induced Liver Injury by Modulation of Nrf2 and Nf- kB Signaling Pathways. SOJ Immunol. 2015;18.

28. Kong DH, Kim YK, Kim MR, Jang JH, Lee S. Emerging Roles of Vascular Cell Adhesion Molecule-1 (VCAM-1) in Immunological Disorders and Cancer. Int J Mol Sci. 2018;2;19(4):E1057 
29. Zhang S, Li H, Xu H, Yang SJ. Effect of gross saponins of Tribulus terrestris on cardiocytes impaired by adriamycin. Yao Xue Xue Bao. 2010;45(1):31-6.

30. Park YJ, Cho YR, Oh JS, Ahn EK. Effects of Tribulus terrestris on monosodium iodoacetate-induced osteoarthritis pain in rats. Mol Med Rep. 2017;16(4):5303-11

31. Zhuang Z, Lian P, Wu X, Shi B, Zhuang M, Zhou R, et al. Abate Cytochrome $C$ induced apoptosome to protect donor liver against ischemia reperfusion injury on rat liver transplantation model. Am J TransI Res. 2016;8(4):1738-47.

32. Kostakis ID, Zavras N, Damaskos C, Sakellariou S, Korkolopoulou P, Misiakos EP, et al. Erythropoietin and sildenafil protect against ischemia/ reperfusion injury following testiculartorsion in adult rats. Exp Ther Med. 2017;13(6):3341-7.

33. Abedi R, Eimani H, Pashaee RS, Eftekhari YP, Shahverdi AH, Mokhber ME. Evaluation effects of allopurinol and $\mathrm{FSH}$ on reduction of ischemia reperfusion injury and on preservation of follicle after heterotopic auto-transplantation of ovarian tissue in mouse. Reprod Med Biol. 2013;13(1):29-35.
34. Jankowska K. Premature ovarian failure. Prz Menopauzalny. 2017;16:51-6.

35. Tavana S, Azarnia M, Valojerdi MR, Shahverdi A. Hyaluronic acid-based hydrogel scaffold without angiogenic growth factors enhances ovarian tissue function after autotransplantation in rats. Biomed Mater. 2016;11(5):055006.

36. Durlinger AL, Gruijters MJ, Kramer P, Karels B, Ingraham HA, Nachtigal MW, et al. Anti Müllerian hormone inhibits initiation of primordial follicle growth in the mouse ovary. Endocrinology. 2002;143(3):1076-84.

37. Kart C, Aran T, Guven S, Karahan SC, Yulug E. Acute increase in plasma D-dimer level in ovarian torsion: An experimental study. Hum Reprod. 2011;26(3):564-8.

38. lijima K, Jiang JY, Shimizu T, Sasada H, Sato E. Acceleration of follicular development by administration of vascular endothelil growth factor in cycling female rats. J Reprod Dev. 2005;51(1):161-8.

39. Tunçkiran A, Cayan S, Bozlu M, Yilmaz N, Acar D, Akbay E. Protective effect of vascular endothelial growth factor on histologic changes in testicular ischemia-reperfusion injury. Fertil Steril. 2005;84(2):468-73.

\section{PICTORIAL ABSTRACT}
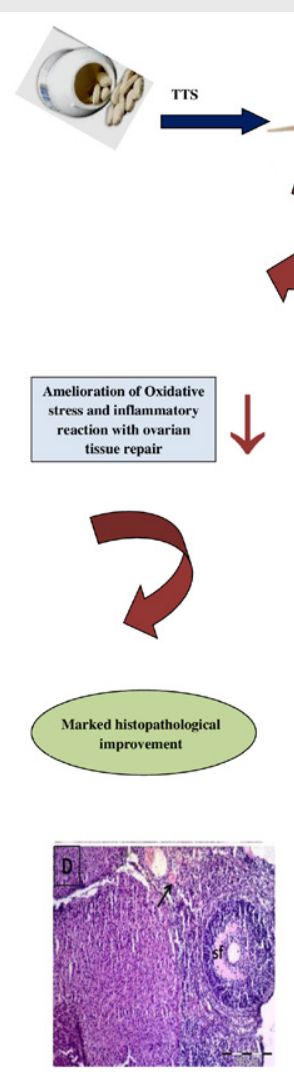
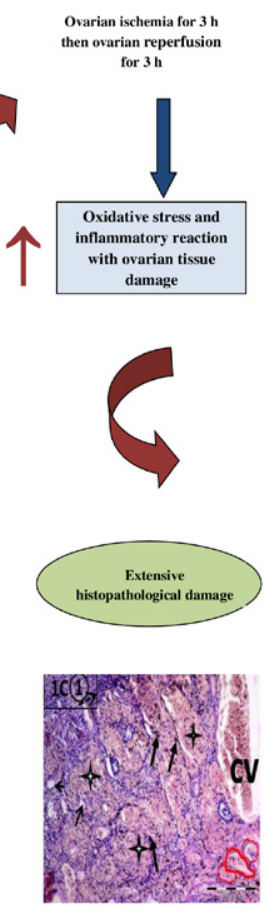

\section{SUMMARY}

This study proved that TTS presented a potential new therapy for ovarian $\mathrm{I} / \mathrm{R}$ as it has the ability to protect the ovaries from ovarian ischemic injury and promoting their function with up regulation of the pituitarygonadal axis, through down-regulation of NF- $\mathrm{BB} / \mathrm{iNOS} /$ NO/ TNF- $\alpha$ pathway along with modulation of HO-1 and VEGF-A expression with inhibition of oxidative stress, inflammatory pathways, apoptotic pathways and promoting ovarian angiogenesis subsequently.

\section{About Authors}

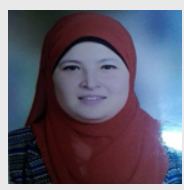

Asmaa Mohamed Abdel-Aziz is an assistant professor at the Department of Pharmacology, Minia University, Minia, Egypt. Dr. Abdel-Aziz elaborates projects that focus on the molecular fundamental mechanisms underlying the ameliorating effects of various pharmacological agents in rodent models of ischemia-reperfusion in ovaries and liver. She is also operating research with a focus on Alzheimer's disease and intestinal injury. In this regard, she uses a combination of approaches ranges from histopathological, biochemical to immunological to provide effective novel therapies in her research studies.

Hanaa Hassanein Mohammed, Departments of Histology and Cell Biology, Faculty of Medicine, Minia University, Minia University, 61511 Minia, Egypt. had a great interest in histopathological finding in different pathology models and had a multiple publication in different models

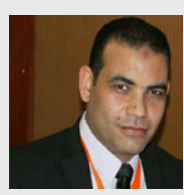

Osama Abdelazem, Lecturer of Obstetrics \& Gynecology , Faculty of Medicine, AlAzhar University, Assuit, Egypt.

have a great interest in female health in both human and rodent, had many publications on ovarian disorders along with uterine pathology

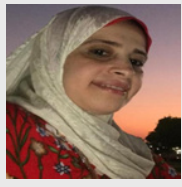

Rasha Fouad Ahmed, is an assistant professor at the Department of medical biochemistry , Minia University, Minia, Egypt. Dr. Rasha Fouad Ahmed share in projects that focus on the molecular mechanisms underlying the various pathology in different rodent models 
Yasmine F. Ibrahim is an Assistant Professor at the Department of Pharmacology, Minia University, Minia, Egypt. Dr. Ibrahim is conducting recent researches studying the role of cytokines as IL-6 and $\mathrm{IL}-1 \mathrm{~b}$, and their receptor blocking drugs as tocilizumab and diacerein, respectively, in ameliorating various disease conditions including sepsis, polycystic ovarian disease, and intestinal ischemia. In this regard, she utilizes clinically relevant rat models, and molecular biology techniques in exploring novel mechanistic insights in the disciplines of cardiovascular, immuno-, gastrointestinal, endocrinal, and genito-urinary pharmacology.

Cite this article: Abdel-Aziz AM, Mohammed HH, Abdelazem O, Ahmed RF, Ibrahim YF. Tribulus terrestris Saponins Improve Ovarian Ischemia-reperfusion Injury in Female Rats: Modulation of Vascular Endothelial Growth Factor-A and Hemeoxygenase-1. Indian J of Pharmaceutical Education and Research. 2021;55(1):240-8. 